\title{
0369 SAFETY OF HOUSEHOLD APPLIANCES FOR ALL
}

S Russell* Correspondence: ANEC, Av. de Tervueren 32, Box 27, Brussels 1040, Belgium

\subsection{6/ip.2010.029215.369}

Consumers expect electrical household appliances to be safe, for themselves, their children and the older members of their families. Yet present international electrical product safety standards (IEC 60335) state that they do not. In general, take into account persons (including children) whose physical, sensory or mental capabilities; or lack of experience and knowledge prevents them from using the appliance safely without supervision or instruction. ANEC has evidence that children and older consumers do independently use appliances such as hairdryers and toasters. Considering the growing ageing European population and that older people get injured especially in the home setting such as bathrooms and kitchens, ANEC believes that standards can be successfully used to help make products and services safe for as many consumers as possible, irrespective of their age or abilities. People living alone are more likely to continue using these products than those living with other people, where help is likely to be more readily available. However, the majority of seniors wish to continue to live in their own homes for as long as possible but many appliances are not designed to meet their changing needs as they age. 
Since 2005, ANEC has been successfully making proposals to change a range of appliance standards to make them safer for all. In November 2009, the first set of revised standards was approved and should be implemented by manufactures in the coming months. ANECs presentation will explain what is missing in these safety standards, our methodology to revise them and proposes an international roadmap to deliver electrical product safety for all consumers. 